\title{
Gnomoniopsis chinensis (Gnomoniaceae, Diaporthales), a new fungus causing canker of Chinese chestnut in Hebei Province, China
}

\author{
Ning Jiang', Ling-Yu Liang', Cheng-Ming Tian' \\ I The Key Laboratory for Silviculture and Conservation of the Ministry of Education, Beijing Forestry Univer- \\ sity, Beijing 100083, China \\ Corresponding author: Cheng-Ming Tian (chengmt@bjfu.edu.cn) \\ Academic editor: Huzefa Raja | Received 14 February 2020 | Accepted 17 April 2020 | Published 14 May 2020 \\ Citation: Jiang N, Liang L-Y, Tian C-M (2020) Gnomoniopsis chinensis (Gnomoniaceae, Diaporthales), a new \\ fungus causing canker of Chinese chestnut in Hebei Province, China. MycoKeys 67: 19-32. https://doi.org/10.3897/ \\ mycokeys.67.51133
}

\begin{abstract}
Chinese chestnut (Castanea mollissima) is an important crop tree species in China. However, branch canker and fruit rot are two kinds of severe diseases, which weaken the host and decrease chestnut production. During our investigations into chestnut diseases in China, several fungi have been confirmed as casual agents in previous studies, namely Aurantiosacculus castaneae, Cryphonectria neoparasitica, Cry. parasitica, Endothia chinensis and Gnomoniopsis daii. In this study, a new canker pathogen is introduced based on morphology, phylogeny and pathogenicity. Typical Gnomoniopsis canker sign of wide, orange tendrils emerging from hosts' glaucous lenticels were obvious on the diseased trees in the field. Symptomatic branches or bark on stems from different chestnut plantations were sampled and isolated, then strains were identified by comparisons of DNA sequence data for the nuclear ribosomal internal transcribed spacer (ITS), partial translation elongation factor- $1 \alpha$ (tefl) and $\beta$-tubulin (tub2) gene regions as well as morphological features. As a result, these strains appeared different from any known Gnomoniopsis species. Hence, we propose a novel species named Gnomoniopsis chinensis. Pathogenicity was further tested using the ex-type strain (CFCC 52286) and another strain (CFCC 52288) on both detached branches and 3-year-old chestnut seedlings. The inoculation results showed that Gnomoniopsis chinensis is mildly pathogenic to Chinese chestnut. However, further studies are required to confirm its pathogenicity to the other cultivated Castanea species in America, Europe and Japan.
\end{abstract}

\section{Keywords}

Castanea mollissima, chestnut disease, taxonomy

Copyright Ning Jiang et al. This is an open access article distributed under the terms of the Creative Commons Attribution License (CC BY 4.0), which permits unrestricted use, distribution, and reproduction in any medium, provided the original author and source are credited. 


\section{Introduction}

The Chinese chestnut (Castanea mollissima), as well as the American chestnut ( $C$. dentata), the European chestnut ( $C$. sativa) and the Japanese chestnut (C. crenata), are known as the four main cultivated sweet chestnut species in the world (Conedera et al. 2004; Yi 2017). In recent studies, several important fungal pathogens have been reported from chestnut trees, including Aurantiosacculus castaneae, Cryphonectria neoparasitica, Cry. parasitica, Endothia chinensis and Gnomoniopsis daii from C. mollissima (Jiang et al. 2018a, 2019b; Jiang and Tian 2019); Cry. parasitica, G. smithogilvyi (syn. G. castaneae), Phytophthora cinnamomi and Sirococcus castaneae from C. sativa (Anagnostakis 1987; Visentin et al. 2012; Shuttleworth et al. 2013; Meyer et al. 2017; Shuttleworth and Guest 2017; Rigling and Prospero 2018; Akilli Şimşek et al. 2019; Lione et al. 2019). In China, Castanea mollissima is widely cultivated for its gluten-free, low fat, and cholesterol-free chestnuts ( $\mathrm{Lu}$ and Guo 2017), but suffering from several fungal diseases (Li et al. 2006; Zhang et al. 2009).

The fungal genus Gnomoniopsis (Gnomoniaceae, Diaporthales) includes species all occurring in plant tissues as pathogens, endophytes or saprobes (Danti et al. 2002; Rossman et al. 2007; Walker et al. 2010; Sogonov et al. 2008). Until now, Gnomoniopsis species have been found on hosts from three plant families, Fagaceae, Onagraceae and Rosaceae (Sogonov et al. 2008; Walker et al. 2010). Two species occur as pathogens on Castanea species (family Fagaceae), i.e. Gnomoniopsis smithogilvyi (syn. G. castaneae) and G. daii (Crous et al. 2012; Jiang and Tian 2019). Gnomoniopsis smithogilvyi and $G$. castaneae were proposed by two independent studies, from rotten fruits of Castanea sativa (Crous et al. 2012; Visentin et al. 2012). However, Shuttleworth et al. (2015) proved that Gnomoniopsis smithogilvyi and G. castaneae are conspecific based on a comparative morphological analysis and five-marker phylogenetic analysis. The fungal name Gnomoniopsis smithogilvyi was published earlier than G. castaneae, hence G. smithogiluyi has priority over G. castaneae.

Gnomoniopsis smithogilvyi is an important nut rot agent on chestnut nuts, an endophyte in asymptomatic flowers, leaves and stems, and a saprobe on dead burrs and branches (Crous et al. 2012; Visentin et al. 2012). Moreover, this species has been reported as a severe bark pathogen on Castanea in several countries (Dar and Rai 2013, 2015; Pasche et al. 2016; Lewis et al. 2017; Trapiello et al. 2018; Lione et al. 2019). In China, Gnomoniopsis from rotten Chinese chestnut has proved to be a different species, namely Gnomoniopsis daii (Jiang and Tian 2019). In this study, we focused on the symptom, taxonomy and pathogenicity aspects of Gnomoniopsis species from cankered tissues on Chinese chestnut trees.

\section{Materials and methods}

Sample collection and isolation

During 2016 to 2019, investigations were conducted in chestnut plantations of nine provinces/municipalities in China, including Beijing, Fujian, Hebei, Hubei, Hunan, 
Liaoning, Shandong, Shaanxi and Tianjin. Typical Gnomoniopsis canker symptoms were only observed in Hebei Province (Fig. 1). Symptomatic barks from stems and cankered branches were collected in brown paper bags and transported to the laboratory for fungal isolations and further study. Single conidial isolates were acquired from asexual fruiting structures by removing a mucoid conidial mass from pycnidial ostioles, and spreading the suspension on the surface of potato dextrose agar (PDA; $200 \mathrm{~g}$ potatoes, $20 \mathrm{~g}$ dextrose, $20 \mathrm{~g}$ agar per L). Agar plates were incubated at $25^{\circ} \mathrm{C}$ to induce germination of conidia. After inoculation for up to $36 \mathrm{~h}$, single germinating conidia were then transferred to clean plates under a dissecting stereomicroscope with a sterile needle. Specimens and cultures were deposited and maintained in the Museum of Beijing Forestry University (BJFC) and China Forestry Culture Collection Center (CFCC), Beijing, China, respectively.

\section{DNA extraction and phylogenetic analysis}

Genomic DNA was extracted from mycelium grown on PDA using a CTAB (cetyltrimethylammonium bromide) method (Doyle and Doyle 1990). Three partial loci, including the $5.8 \mathrm{~S}$ nuclear ribosomal DNA gene with the two flanking internally transcribed spacer (ITS) regions, the translation elongation factor 1a (tefl), and the $\beta$-tubulin gene 2 (tub2), were amplified using the following primer pairs: ITS1 and ITS4 for ITS (White et al. 1990), EF1-728F and EF1-1567R for tef1 (Carbone and Kohn 1999), and Bt2a and Bt2b for tub2 (Glass and Donaldson 1995). The PCR conditions were: initial denaturation step of $5 \mathrm{~min}$ at $94^{\circ} \mathrm{C}$, followed by 35 cycles of $30 \mathrm{~s}$ at $94^{\circ} \mathrm{C}, 50 \mathrm{~s}$ at $48^{\circ} \mathrm{C}$ (ITS) or $54^{\circ} \mathrm{C}$ (tef1) or $52^{\circ} \mathrm{C}$ (tub2), and $1 \mathrm{~min}$ at $72^{\circ} \mathrm{C}$, and a final elongation step of $7 \mathrm{~min}$ at $72^{\circ} \mathrm{C}$. The PCR amplification products were scored visually by electrophoresis in $2 \%$ agarose gels. The DNA sequencing was performed using an ABI PRISM 3730XL DNA Analyzer with BigDye Terminater Kit v.3.1 (Invitrogen) at the Shanghai Invitrogen Biological Technology Company Limited (Beijing, China). To assess the phylogenetic position of our isolates within the genus Gnomoniopsis, phylogenetic analyses were performed based on combined ITS, tef1 and tub2 sequence data, with Sirococcus castaneae (CBS 142041) and Apiognomonia errabunda (CBS 342.86) selected as outgroup taxa. The GenBank accession numbers of sequences used in the analysis are given in Table 1, which were aligned and edited manually in MEGA6 (Tamura et al. 2013). Maximum likelihood (ML) analysis was used for phylogenetic inferences of the concatenated alignments. ML analysis was implemented on the CIPRES Science Gateway portal using RAxML-HPC BlackBox v. 8.2.10 (Stamatakis 2014).

\section{Morphological identification and characterization}

Species identification was based on morphological features of the asexual fruiting bodies produced on infected plant tissues, supplemented by cultural characteristics. 

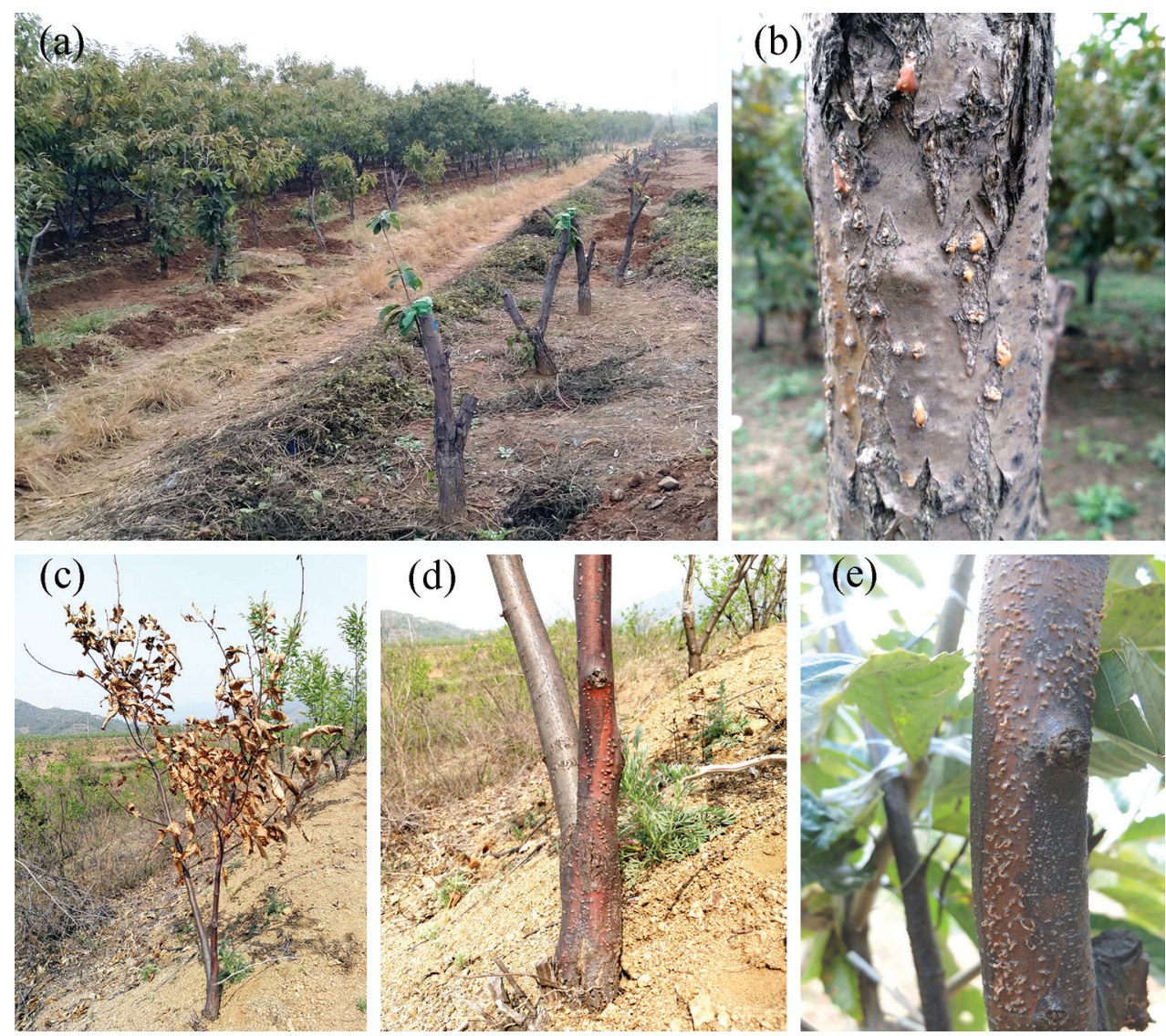

(d)

Figure I. Symptoms caused by Gnomoniopsis chinensis on Chinese chestnut (Castanea mollissima) a, b severe cankers on adult trees $\mathbf{c}$ a dead young tree $\mathbf{d}$ lesion with conidiomata on the bark near the root $\mathbf{e}$ lesion with conidiomata on the stem.

Hence, cross-sections were prepared by hand using a double-edge blade. Morphological characteristics of the fruiting bodies including: size of conidiomata and locules; size and shape of conidiophores and conidia were determined under a Nikon AZ100 dissecting stereomicroscope. More than 20 fruiting bodies were sectioned, and 50 conidia were selected randomly for measurement using a Leica compound microscope (LM, DM 2500). Cultural characteristics of isolates incubated on PDA in the dark at $25^{\circ} \mathrm{C}$ were recorded, including the colony color and pycnidium structures (Rayner 1970).

\section{Pathogenicity trials}

Two isolates of Gnomoniopsis chinensis (ex-type strain: CFCC 52286; CFCC 52288) were used for inoculations, and agar plugs were used as the negative control. Isolates 
Table I. Isolates and GenBank accession numbers used in this study.

\begin{tabular}{|c|c|c|c|c|c|c|}
\hline \multirow[t]{2}{*}{ Species } & \multirow[t]{2}{*}{ Country } & \multirow[t]{2}{*}{ Host } & \multirow[t]{2}{*}{ Strain } & \multicolumn{3}{|c|}{ GenBank Accession Number } \\
\hline & & & & ITS & $t u b 2$ & tef1 \\
\hline Apiognomonia veneta & France & Platanus occidentalis & CBS 342.86 & DQ313531 & EU219235 & DQ318036 \\
\hline Gnomoniopsis alderdunensis & USA & Rubus pedatus & CBS 125679 & GU320826 & GU320788 & GU320813 \\
\hline Gnomoniopsis alderdunensis & USA & Rubus parviflorus & CBS 125680 & GU320825 & GU320787 & GU320801 \\
\hline Gnomoniopsis alderdunensis & USA & Rubus parviflorus & CBS 125681 & GU320827 & GU320789 & GU320802 \\
\hline Gnomoniopsis chamaemori & Finland & Rubus chamaemorus & CBS 804.79 & GU320817 & GU320777 & GU320809 \\
\hline Gnomoniopsis chinensis & China & Castanea mollissima & CFCC 52286 & MG866032 & MH545366 & MH545370 \\
\hline Gnomoniopsis chinensis & China & Castanea mollissima & CFCC 52287 & MG866033 & MH545367 & MH545371 \\
\hline Gnomoniopsis chinensis & China & Castanea mollissima & CFCC 52288 & MG866034 & MH545368 & MH545372 \\
\hline Gnomoniopsis chinensis & China & Castanea mollissima & CFCC 52289 & MG866035 & MH545369 & MH545373 \\
\hline Gnomoniopsis clavulata & USA & Quercus falcata & CBS 121255 & EU254818 & EU219211 & GU320807 \\
\hline Gnomoniopsis comari & Finland & Comarum palustre & CBS 806.79 & EU254821 & EU219156 & GU320810 \\
\hline Gnomoniopsis comari & Finland & Comarum palustre & CBS 807.79 & EU254822 & GU320779 & GU320814 \\
\hline Gnomoniopsis comari & Switzerland & Comarum palustre & CBS 809.79 & EU254823 & GU320778 & GU320794 \\
\hline Gnomoniopsis daii & China & Castanea mollissima & CFCC 54043 & MN598671 & MN605517 & MN605519 \\
\hline Gnomoniopsis daii & China & Castanea mollissima & CMF002B & MN598672 & MN605518 & MN605520 \\
\hline Gnomoniopsis fructicola & USA & Fragaria vesca & CBS 121226 & EU254824 & EU219144 & GU320792 \\
\hline Gnomoniopsis fructicola & France & Fragaria sp. & CBS 208.34 & EU254826 & EU219149 & GU320808 \\
\hline Gnomoniopsis fructicola & USA & Fragaria sp. & CBS 125671 & GU320816 & GU320776 & GU320793 \\
\hline Gnomoniopsis guttulata & Bulgaria & Agrimonia eupatoria & MS 0312 & EU254812 & NA & NA \\
\hline Gnomoniopsis idaeicola & USA & Rubus sp. & CBS 125672 & GU320823 & GU320781 & GU320797 \\
\hline Gnomoniopsis idaeicola & USA & Rubus pedatus & CBS 125673 & GU320824 & GU320782 & GU320798 \\
\hline Gnomoniopsis idaeicola & France & Rubus sp. & CBS 125674 & GU320820 & GU320780 & GU320796 \\
\hline Gnomoniopsis idaeicola & USA & Rubus procerus & CBS 125675 & GU320822 & GU320783 & GU320799 \\
\hline Gnomoniopsis idaeicola & USA & Rubus procerus & CBS 125676 & GU320821 & GU320784 & GU320811 \\
\hline Gnomoniopsis macounii & USA & Spiraea sp. & CBS 121468 & EU254762 & EU219126 & GU320804 \\
\hline Gnomoniopsis occulta & USA & Potentilla sp. & CBS 125677 & GU320828 & GU320785 & GU320812 \\
\hline Gnomoniopsis occulta & USA & Potentilla sp. & CBS 125678 & GU320829 & GU320786 & GU320800 \\
\hline Gnomoniopsis paraclavulata & USA & Quercus alba & CBS 123202 & GU320830 & GU320775 & GU320815 \\
\hline Gnomoniopsis racemula & USA & Chamerion angustifolium & CBS 121469 & EU254841 & EU219125 & GU320803 \\
\hline Gnomoniopsis sanguisorbae & Switzerland & Sanguisorba minor & CBS 858.79 & GU320818 & GU320790 & GU320805 \\
\hline Gnomoniopsis smithogilvyi & Australia & Castanea sp. & CBS 130190 & JQ910642 & JQ910639 & KR072534 \\
\hline Gnomoniopsis smithogilvyi & Australia & Castanea sp. & CBS 130189 & JQ910644 & JQ910641 & KR072535 \\
\hline Gnomoniopsis smithogilvyi & Australia & Castanea sp. & CBS 130188 & JQ910643 & JQ910640 & KR072536 \\
\hline Gnomoniopsis smithogilvyi & Italy & Castanea sativa & MUT 401 & HM142946 & KR072532 & KR072537 \\
\hline Gnomoniopsis smithogilvyi & New Zealand & Castanea sativa & MUT 411 & HM142948 & KR072533 & KR072538 \\
\hline Gnomoniopsis tormentillae & Switzerland & Potentilla sp. & CBS 904.79 & EU254856 & EU219165 & GU320795 \\
\hline Sirococcus castaneae & Switzerland & Castanea sativa & CBS 142041 & KX929744 & KX958443 & KX929710 \\
\hline
\end{tabular}

Note: NA, not applicable. Strains in this study are identified in bold.

were grown on PDA for five days at $25^{\circ} \mathrm{C}$ before the tests. Inoculations were performed on detached branches and 3-year-old seedlings of Castanea mollissima, respectively. The detached branches and young seedling were collected from Hebei Province where the disease is emerging. The healthy chestnut branches $(2 \mathrm{~cm}$ in diameter $)$ were sampled from an adult chestnut tree and cut into pieces of $20 \mathrm{~cm}$ length. A total of 30 fresh and healthy branches and 15 seedlings were used for the pathogenicity tests. Ten branches and five seedlings were inoculated with each isolate and the negative control. For incubations, incisions were made on the middle of the detached branches and $1 \mathrm{~cm}$ above the midpoint of the seedling stem to expose the cambium using a 5-mmdiameter cork borer. Discs of agar were cut from the actively growing margins of the 
cultures and these were placed into wounds of the same size on the chestnut barks. Inoculated wounds and ends of inoculated branches were sealed with parafilm to reduce desiccation and the chance of contamination. The tested seedlings and branch segments were maintained in the greenhouse randomly at $25^{\circ} \mathrm{C}$ under natural light conditions. Detached branches were inoculated in November 2017, and the young seedlings were tested in July 2019. The results from detached branches were evaluated after one month, and seedlings after three months, by measuring the lengths of the lesions on the cambium. The re-isolations were made from the resultant lesions from all tested branches and seedlings by cutting small pieces of discolored xylem and placing them onto the PDA plates. Re-isolations were identified based on morphology on PDA and ITS sequences. Differences among isolates in lesion length were analyzed by one-way analysis of variance (ANOVA) followed by least significant difference (LSD) tests. Statistical analysis was carried out by R software (version 3.4.3.) and considered as significant at $\mathrm{p}<0.05$.

\section{Results}

\section{Phylogenetic analyses}

The final combined ITS-tef1-tub2 matrix of Gnomoniopsis included 35 ingroup and two outgroup taxa, comprising 1364 alignment characters. Of these, 783 characters were constant, 117 variable characters were parsimony-uninformative and 464 characters were parsimony informative. The phylogenetic tree obtained from ML analysis is shown in Figure 2, indicating that all isolates from the present study are phylogenetically different from other known species with 100\% ML bootstrap support.

\section{Taxonomy}

\section{Gnomoniopsis chinensis C.M. Tian \& N. Jiang, sp. nov.}

MycoBank No: 823868

Figures 3, 4

Etymology. Named after the country where it was first collected.

Description. Pathogenic on stems and branches of Castanea mollissima. Conidiomata pseudostromatic, globose to pulvinate, occurring separately, yellow to orange, semi-immersed in bark, 400-1000 $\mu \mathrm{m}$ high, 500-1500 $\mu \mathrm{m}$ diam, unilocular, single ostiolate, forming long, wide orange tendrils, 1500-2000 $\mu \mathrm{m} \times 400-500 \mu \mathrm{m}$. Conidiophores indistinct, often reduced to conidiogenous cells. Conidiogenous cells oval, hyaline, 1-celled, 6-12 $\mu \mathrm{m}$. Conidia oval, oblate, fusiform, straight to curved, hyaline, $2-3$ guttules, $(6.0-) 6.5-8.5(-9.0) \times(2.2-) 2.7-3(-3.5) \mu \mathrm{m}($ mean $=7.5 \times 2.7 \mu \mathrm{m})$. 


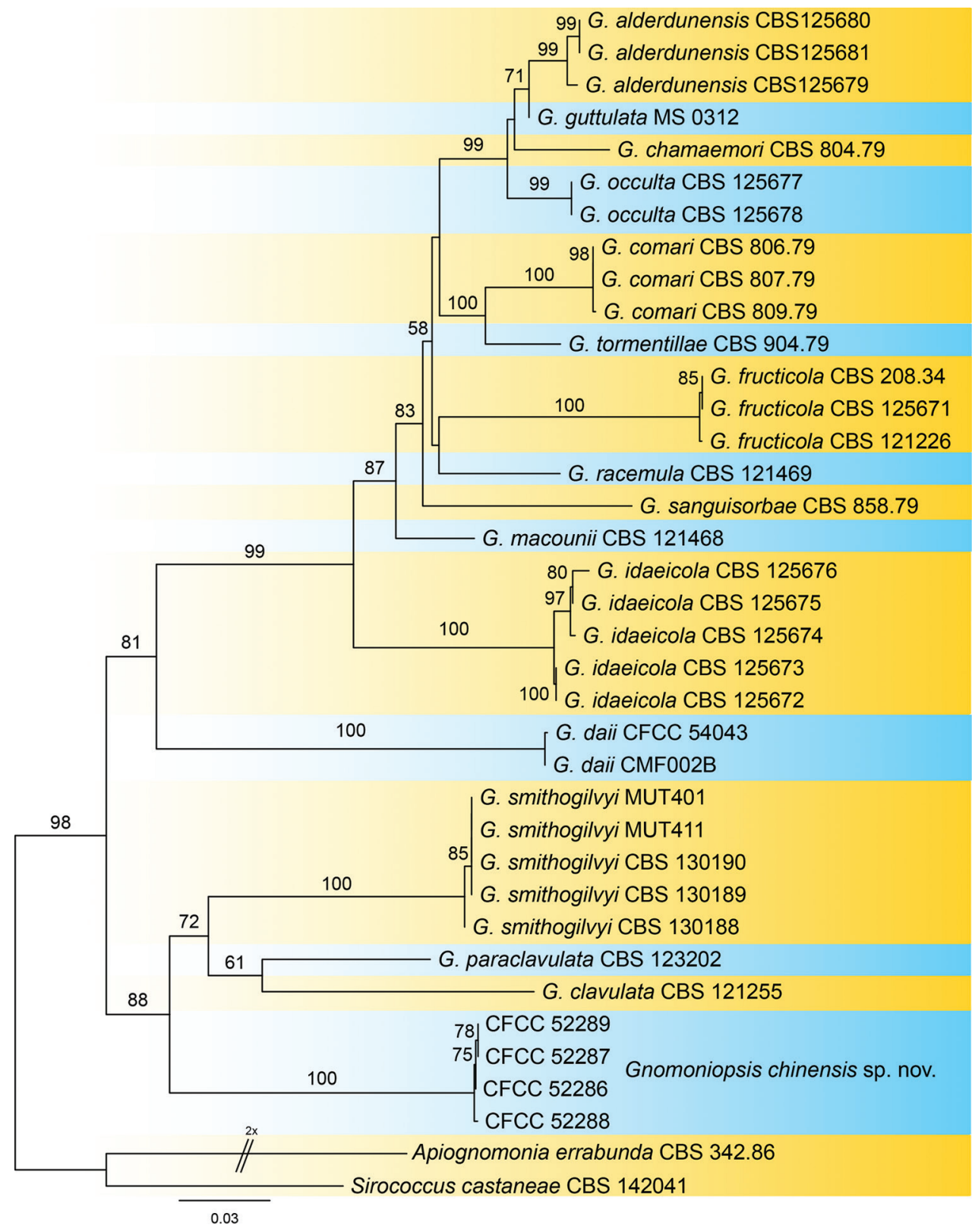

Figure 2. Consensus tree resulting from a RAxML analysis of combined ITS, tef1 and tub2 sequence alignment for species of Gnomoniopsis. The scale bar represents the expected number of changes per site.

Culture characters. Colonies on PDA attaining $90 \mathrm{~mm}$ after 20 days at $25^{\circ} \mathrm{C}$, flat, velutinous to shortly woolly, dark brown in center, gradually lightening to pale grey at margin; margin diffuse; reverse of almost same colors as surface. 

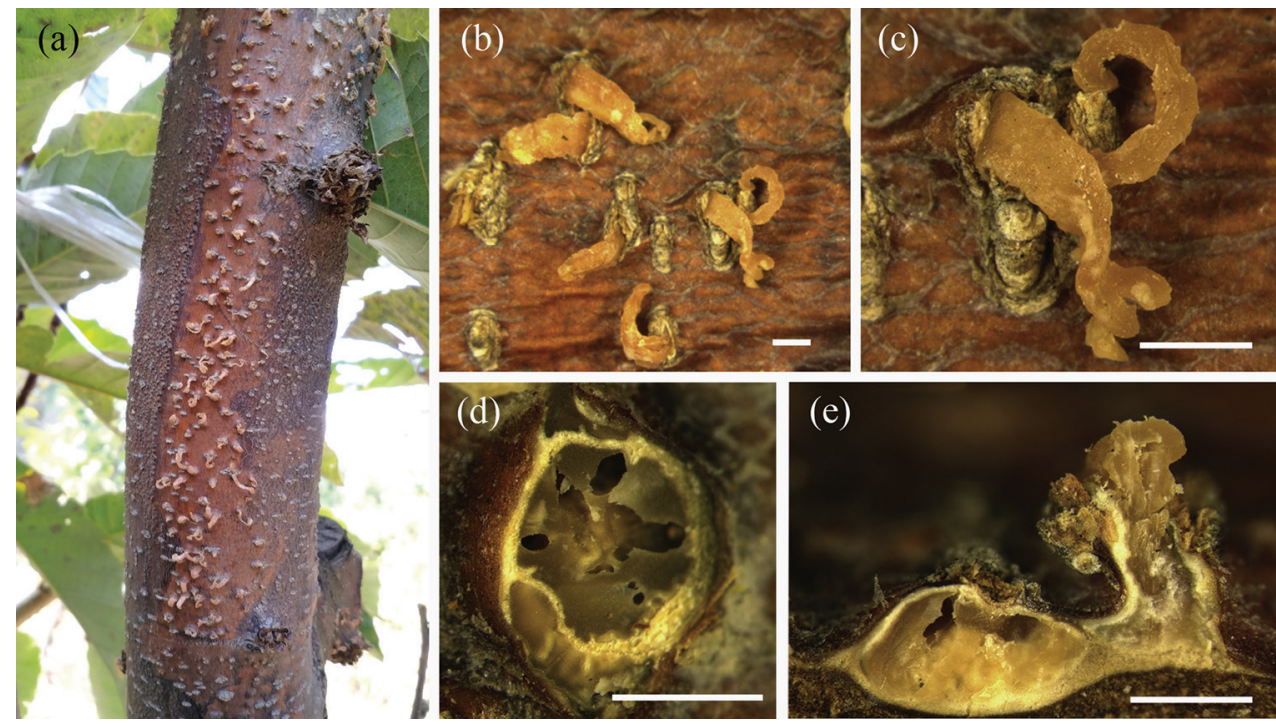

Figure 3. Conidiomata of Gnomoniopsis chinensis from Castanea mollissima (BJFC-S1380, holotype) a-c habit of conidiomata on the chestnut stem $\mathbf{d}$ transverse sections through conidiomata $\mathbf{e}$ longitudinal sections through conidiomata. Scale bars: $1 \mathrm{~mm}(\mathbf{b}-\mathbf{e})$.
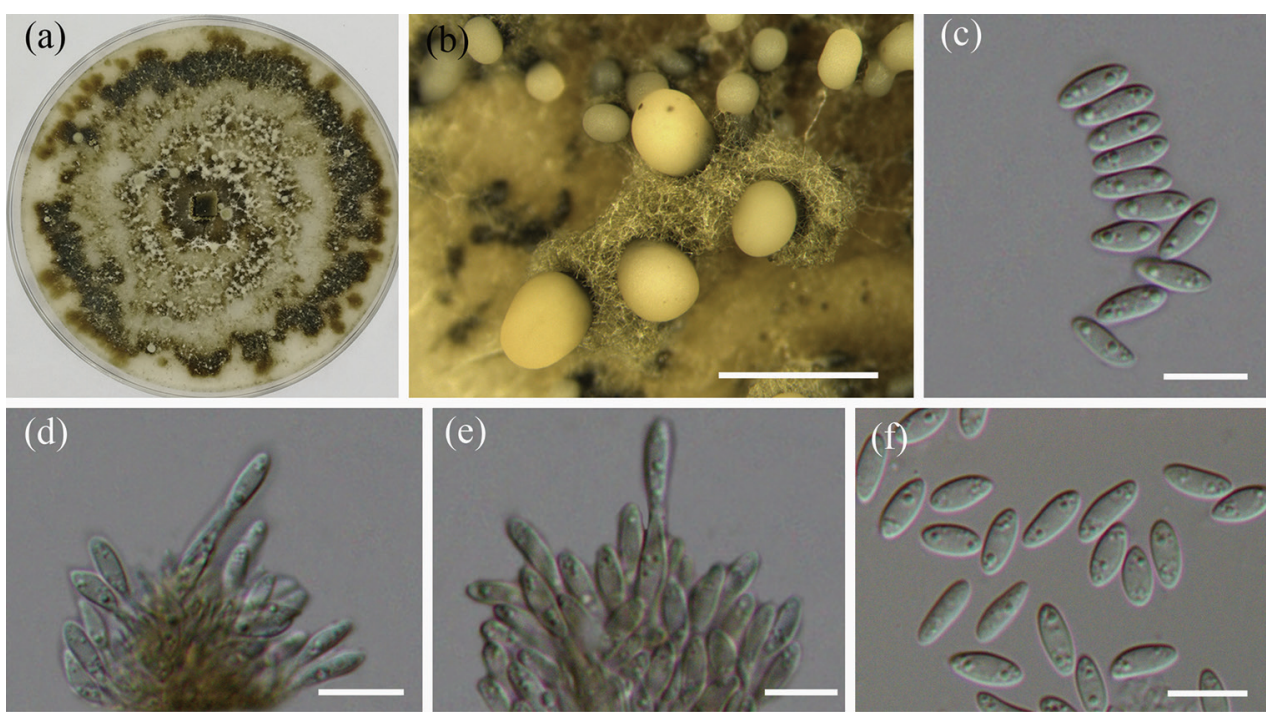

Figure 4. Morphology of Gnomoniopsis chinensis from PDA (CFCC 52286, ex-type culture) a colonies on PDA b conidiomata formed on PDA c, $\mathbf{f}$ conidia $\mathbf{d}$, e conidiogenous cells. Scale bars: $1 \mathrm{~mm}(\mathbf{b})$; $10 \mu \mathrm{m}(\mathbf{c}-\mathbf{f})$.

Specimens examined. China, Hebei Province, Chengde City, chestnut plantation, $40^{\circ} 24^{\prime} 32.16^{\prime \prime} \mathrm{N}, 117^{\circ} 28^{\prime} 56.24^{\prime \prime} \mathrm{E}, 262 \mathrm{~m}$ asl, on stems and branches of Castanea mollissima, Ning Jiang, 11 October 2017 (BJFC-S1380, holotype; ex-type culture, CFCC 52286). Hebei Province, Qinhuangdao City, chestnut plantation, 40²2'52.32"N, 
$119^{\circ} 11^{\prime} 52.18$ "E, $246 \mathrm{~m}$ asl, on branches and twigs of Castanea mollissima, Ning Jiang, 14 October 2017 (BJFC-S1382, paratype; living culture, CFCC 52288). Hebei Prov-

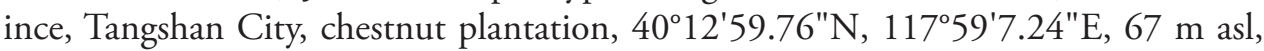
on stems and branches of Castanea mollissima, Ning Jiang, 18 October 2017 (BJFCS1383; living culture, CFCC 52289).

Notes. Three Gnomoniopsis species have been discovered from the host genus Castanea. They share similar conidial dimension $(6.0-9.0 \times 2.2-3.5 \mu \mathrm{m}$ in Gnomoniopsis chinensis vs. $5.0-8.0 \times 2.0-3.5 \mu \mathrm{m}$ in $G$. daii vs. 6.0-9.5 $\times 2.0-4.0 \mu \mathrm{m}$ in G. smithogilvyi) (Crous et al. 2012; Jiang and Tian 2019). However, we can distinguish them easily by the phylogram of ITS, tef1 and tub2 (Fig. 2). In addition, Gnomoniopsis chinensis and G. daii inhabit the Chinese chestnut (Castanea mollissima), but G. smithogilvyi on the European chestnut (C. sativa) and C. crenata $\times$ C. sativa hybrids.

\section{Pathogenicity trials}

One month after inoculation on detached branches, the two Gnomoniopsis chinensis isolates produced lesions in the cambium of detached chestnut branches. In contrast, there was no lesion development in any of the negative control inoculations (Fig. 5). The lesion size of the two Gnomoniopsis chinensis isolates (CFCC 52286 and CFCC 52288) showed no significantly difference, while both of them were significantly longer than the negative control $(\mathrm{P}<0.05)$. Gnomoniopsis chinensis was consistently re-isolated from lesions.

Three months after inoculation on young seedlings, two isolates Gnomoniopsis chinensis and the negative control, produced minor lesions (Fig. 6). Statistical analyses of data showed no significant difference among two isolates Gnomoniopsis chinensis and the negative control $(\mathrm{P}<0.05)$. However, Gnomoniopsis chinensis was still re-isolated successfully from the minor lesions caused by CFCC 52286 and CFCC 52288 and not from the negative control inoculations.

(a)

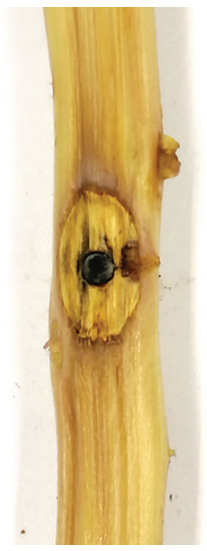

(b)

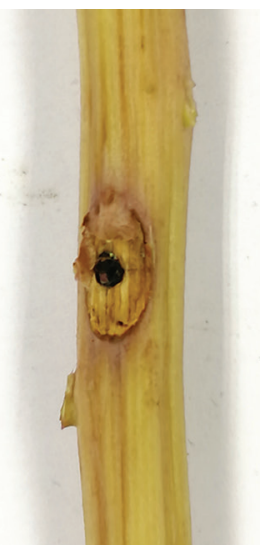

(c)

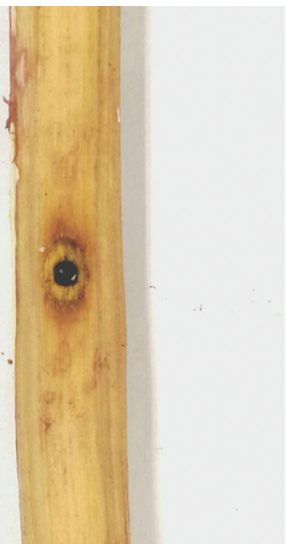

Figure 5. Lesions resulting from inoculation of Gnomoniopsis chinensis onto detached Castanea mollissima branches, and wound response on the negative control a CFCC 52288 b CFCC 52286 c negative control. 

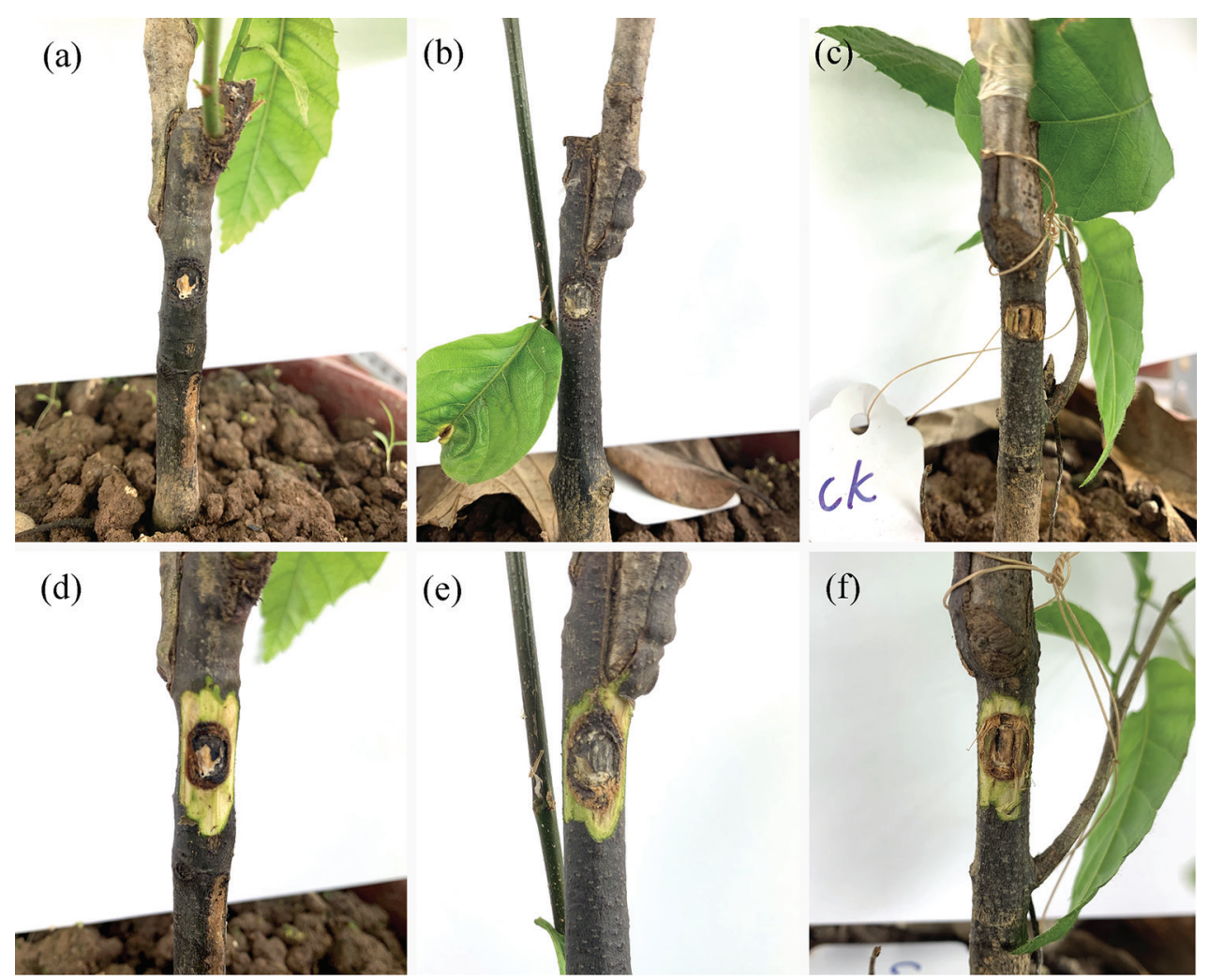

(e)
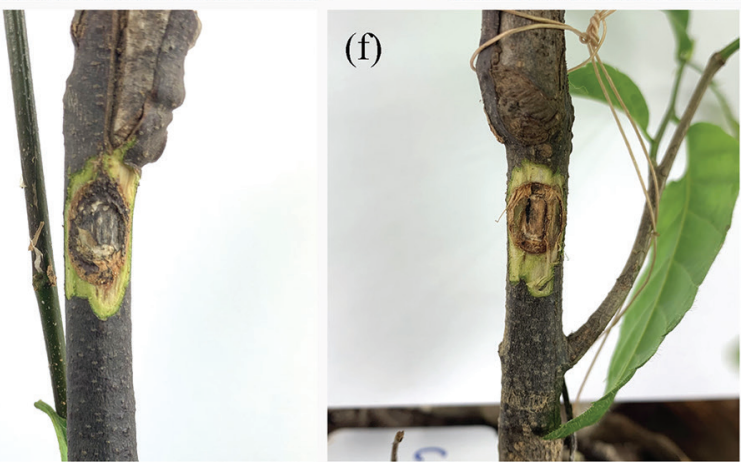

Figure 6. Lesions resulting from inoculation of Gnomoniopsis chinensis onto 3-year-old Castanea mollissima seedlings, and wound response on the negative control a, d CFCC 52288 b, e CFCC 52286 c, $\mathbf{f}$ negative control. Row 1: lesions on the bark; row 2: lesions beneath the bark.

\section{Discussion}

In the past years, our team focused on the fungi inhabiting Chinese chestnut (Castanea mollissima) trees from their taxonomy and pathogenicity aspects. Several fungi including Aurantiosacculus castaneae, Cryphonectria neoparasitica, Cry. parasitica, Endothia chinensis and Gnomoniopsis daii have been proven to cause branch canker or fruit rot (Jiang et al. 2019b; Jiang and Tian 2019). Other fungi were reported to be associated with branch canker, however, they were not confirmed by incubation tests, including Aplosporella javeedii, Coryneum gigasporum, Co. sinense, Co. suttonii, Co. umbonatum, Cytospora ceratospermopsis, Cy. kuanchengensis, Cy. leucostoma, Cy. myrtagena, Cy. Schulzeri, Cy. xinglongensis, Dendrostoma aurorae, Den. castaneae, Den. castaneicola, Den. chinense, Den. parasiticum, Den. shaanxiense, Den. shandongense, Lopadostoma americanum, Melanops castaneicola, Myrmaecium fulvopruinatum, Neopseudomelanconis castaneae (Jiang et al. 2018b, c, d, 2019a, 2020). Subsequently, Dendrostoma atlanticum and Den. castaneum were reported from European chestnut (Castanea sativa) trees (Jaklitsch and 
Voglmayr 2019). Different Dendrostoma species were discovered from the Chinese and European chestnut stems, branches and twigs, which indicates similar plant and fungi interactions in different continents. Another example is that Gnomoniopsis daii causes Chinese chestnut rot and Gnomoniopsis smithogilvyi causes European chestnut rot (Crous et al. 2012; Jiang and Tian 2019). Interestingly, this study reveals a novel Gnomoniopsis species, $G$. chinensis, as an opportunistic pathogen causing bark cankers on Chinese chestnut, which is different from Gnomoniopsis smithogilvyi causing both nut rot and bark cankers (Crous et al. 2012; Visentin et al. 2012; Dar and Rai 2013, 2015; Pasche et al. 2016; Lewis et al. 2017; Trapiello et al. 2018).

Gnomoniopsis species appear host-specific, inhabiting hosts of three families, viz. Betulaceae, Fagaceae, Rosaceae and Onagraceae (Sogonov et al. 2008; Walker et al. 2010; Visentin et al. 2012; Linaldeddu et al. 2016). Five species have been discovered from fagaceous hosts, and they are similar in conidial size (Table 2). Gnomoniopsis clavulata and G. paraclavulata were recorded on Fagus or Quercus trees (Sogonov et al. 2008). Gnomoniopsis chinensis and $G$. daii were discovered only from Castanea trees. It is hard to distinguish them by the currently known conidial characteristics. However, all currently known Gnomoniopsis species can be successfully distinguished by phylogenetic analysis based on ITS, tef1 and tub2.

Stevanović et al. (2019) reported Gnomoniopsis idaeicola to cause blackberry canker and wilting in Serbia. With the same signs on the host bark, especially the wide, orange tendrils emerging from hosts' glaucous lenticels, Gnomoniopsis chinensis appeared to be an emerging pathogen on Castanea mollissima. Chestnut blight, caused by Cryphonectria parasitica, a notorious bark disease on chestnut trees worldwide (Rigling and Prospero 2018), can be distinguished from chestnut Gnomoniopsis canker, and the presence of mycelial fans in the cambial region. Nowadays, we have characterized the two canker pathogens on Chinese and European chestnut trees, Gnomoniopsis chinensis and $G$. smithogilvyi. They appear not to be very pathogenic to their native hosts, but the pathogenicity to non-native hosts is still unknown. Gnomoniopsis and Cryphonectria belong to the same fungal order Diaporthales, and are similar in some aspects. Hence, more work on these two pathogens is necessary on both Castanea mollissima and $C$. sativa. In addition, considering the high value of the plant genus, Castanea, and the current situation of serious commercial loss caused by various fungi, more comprehensive and detailed investigations are necessary to understand the diversity of microbes on the hosts and their functions.

Table 2. Conidial size of Gnomoniopsis species from fagaceous hosts.

\begin{tabular}{lccc}
\hline Species & Conidial length $(\boldsymbol{\mu m})$ & Conidial width $(\boldsymbol{\mu m})$ & Reference \\
\hline Gnomoniopsis chinensis & $(6.0-) 6.5-8.5(-9.0)$ & $(2.2-) 2.7-3(-3.5)$ & This study \\
Gnomoniopsis clavulata & $(5-) 6-6.5(-8)$ & $(2-) 2.5-3(-4)$ & Sogonov et al. 2008 \\
Gnomoniopsis daii & $(5.0-) 5.5-7.0(-8.0)$ & $2.0-3.5$ & Jiang and Tian 2019 \\
Gnomoniopsis paraclavulata & $(6-) 7.5-8(-9.5)$ & $(2-) 3-3(-3.5)$ & Sogonov et al. 2008 \\
Gnomoniopsis smithogilvyi & $(6.0-) 8(-9.5)$ & $(2.0-) 2.5(-4.0)$ & Crous et al. 2012 \\
\hline
\end{tabular}




\section{Acknowledgements}

This study is financed by National Natural Science Foundation of China (Project No.: 31670647). We are grateful to Chungen Piao, Minwei Guo (China Forestry Culture Collection Center (CFCC), Chinese Academy of Forestry, Beijing.

\section{References}

Akilli Şimşek S, Katircioğlu YZ, Ulubaş Serçe Ç, Çakar D, Rigling D, Maden S (2019) Phytophthora species associated with dieback of sweet chestnut in Western Turkey. Forest Pathology 49: e12533. https://doi.org/10.1111/efp.12533

Anagnostakis SL (1987) Chestnut blight: the classical problem of an introduced pathogen. Mycologia 79: 23-37. https://doi.org/10.1080/00275514.1987.12025367

Carbone I, Kohn LM (1999) A method for designing primer sets for speciation studies in filamentous ascomycetes. Mycologia 91: 553-556. https://doi.org/10.1080/00275514.1 999.12061051

Conedera M, Manetti MC, Giudici F, Amorini E (2004) Distribution and economic potential of the sweet chestnut (Castanea sativa Mill.) in Europe. Ecologia Mediterranea 30: 179-193. https://doi.org/10.3406/ecmed.2004.1458

Crous PW, Summerell BA, Shivas RG, Burgess TI, Decock CA, Dreyer LL, Granke LL, Guest DI, Hardy GESTJ, Hausbeck MK, Hüberli D, Jung T, Koukol O, Lennox CL, Liew ECY, Lombard L, McTaggart AR, Pryke JS, Roets F, Saude C, Shuttleworth LA, Stukely MJC, Vánky K, Webster BJ, Windstam ST, Groenewald JZ (2012) Fungal planet description sheets: 107-127. Persoonia 28: 138-182. https://doi.org/10.3767/003158512X652633

Danti R, Sieber TN, Sanguineti G (2002) Endophytic mycobiota in bark of European beech (Fagus sylvatica) in the Apennines. Mycological Research 106: 1343-1348. https://doi. org/10.1017/S0953756202006779

Dar MA, Rai M (2013) Biological and phylogenetic analyses, evidencing the presence of Gnomoniopsis sp. in India, causing canker of chestnut trees: a new report. Indian Forester 139: 37-42.

Dar MA, Rai M (2015) Gnomoniopsis smithogilvyi, a canker causing pathogen on Castanea sativa: First report. Mycosphere 6: 327-336. https://doi.org/10.5943/mycosphere/6/3/8

Doyle JJ, Doyle JL (1990) Isolation of plant DNA from fresh tissue. Focus 12: 13-15. https:// doi.org/10.2307/2419362

Glass NL, Donaldson GC (1995) Development of primer sets designed for use with the PCR to amplify conserved genes from filamentous ascomycetes. Applied and Environmental Microbiology 61: 1323-1330. https://doi.org/10.1128/AEM.61.4.1323-1330.1995

Jaklitsch WM, Voglmayr H (2019) European species of Dendrostoma (Diaporthales). Mycokeys 59: 1-26. https://doi.org/10.3897/mycokeys.59.37966

Jiang N, Fan XL, Yang Q, Du Z, Tian CM (2018a) Two novel species of Cryphonectria from Quercus in china. Phytotaxa 347: 243-250. https://doi.org/10.11646/phytotaxa.347.3.5

Jiang N, Li J, Piao CG, Guo MW, Tian CM (2018b) Identification and characterization of chestnut branch-inhabiting melanocratic fungi in China. Mycosphere 9: 1268-1289. https://doi.org/10.1111/ppa.13033 
Jiang N, Phillips AJL, Zhang ZX, Tian CM (2018c) Morphological and molecular identification of two novel species of Melanops in China. Mycosphere 9: 1187-1196. https://doi. org/10.5943/mycosphere/9/6/8

Jiang N, Voglmayr H, Tian CM (2018d) New species and records of Coryneum from China. Mycologia 110: 1172-1188. https://doi.org/10.1080/00275514.2018.1516969

Jiang N, Fan XL, Crous PW, Tian CM (2019a) Species of Dendrostoma (Erythrogloeaceae, Diaporthales) associated with chestnut and oak canker diseases in China. Mycokeys 48: 67-96. https://doi.org/10.3897/mycokeys.48.31715

Jiang N, Fan XL, Tian CM (2019b) Identification and pathogenicity of Cryphonectriaceae species associated with chestnut canker in China. Plant Pathology 68: 1132-1145. https:// doi.org/10.5943/mycosphere/9/6/14

Jiang N, Tian CM (2019) An emerging pathogen from rotted chestnut in China: Gnomoniopsis daii sp. nov. Forests 10: 1-1016. https://doi.org/10.3390/f10111016

Jiang N, Yang Q, Fan XL, Tian CM (2020) Identification of six Cytospora species on Chinese chestnut in China. Mycokeys 62: 1-25. https://doi.org/10.3897/mycokeys.62.47425

Lewis A, Gorton C, Rees H, Webber J, Pérez-Sierra A (2017) First report of Gnomoniopsis smithogilvyi causing lesions and cankers of sweet chestnut in the United Kingdom. New Disease Reports 35: 1-20. https://doi.org/10.5197/j.2044-0588.2017.035.020

Li GY, Wei JG, Luo JT, Zhao TK, Liao WJ, Pan XH (2006) Risk analysis of chestnut blight in Guangxi. Journal of Guangxi Agriculture and Biology Science 25: 310-314.

Linaldeddu BT, Deidda A, Scanu B, Franceschini A, Alves A, Abdollahzadeh J, Phillips AJL (2016) Phylogeny, morphology and pathogenicity of Botryosphaeriaceae, Diatrypaceae and Gnomoniaceae associated with branch diseases of hazelnut in Sardinia (Italy). European Journal of Plant Pathology 146: 259-279. https://doi.org/10.1007/s10658-016-0912-z

Lione G, Danti R, Fernandez-Conradi P, Ferreira-Cardoso JV, Lefort F, Marques G, Meyer JB, Prospero S, Radócz L, Robin C, Turchetti T, Vettraino AM, Gonthier P (2019) The emerging pathogen of chestnut Gnomoniopsis castaneae: the challenge posed by a versatile fungus. European Journal of Plant Pathology 153: 671-685. https://doi.org/10.1007/s10658-018-1597-2

Lu C, Guo SJ (2017) Analysis on the nutritional characters and comprehensive evaluation of 16 chestnut germplasm resources. Science and Technology of Food Industry 37: 357-376.

Meyer JB, Trapiello E, Senn-Irlet B, Sieber TN, Cornejo C, Aghayeva D, Gonzalez, AJ, Prospero S (2017) Phylogenetic and phenotypic characterisation of Sirococcus castaneae comb. nov.(synonym Diplodina castaneae), a fungal endophyte of European chestnut. Fungal Biology 121: 625-637. https://doi.org/10.1016/j.funbio.2017.04.001

Pasche S, Calmin G, Auderset G, Crovadore J, Pelleteret P, Mauch-Mani B, Barja F, Paul B, Jermini M, Lefort F (2016) Gnomoniopsis smithogilvyi causes chestnut canker symptoms in Castanea sativa shoots in Switzerland. Fungal Genetics and Biology 87: 9-21. https://doi. org/10.1016/j.fgb.2016.01.002

Rayner RW (1970) A mycological colour chart. Commonwealth Mycological Institute, Kew.

Rigling D, Prospero S (2017) Cryphonectria parasitica, the causal agent of chestnut blight: invasion history, population biology and disease control. Molecular Plant Pathology 19: 7-20. https://doi.org/10.1111/mpp. 12542

Rossman AY, Farr DF, Castlebury LA (2007) A review of the phylogeny and biology of the Diaporthales. Mycoscience 48: 135-144. https://doi.org/10.1007/S10267-007-0347-7 
Shuttleworth LA, Liew ECY, Guest DI (2013) Survey of the incidence of chestnut rot in south-eastern Australia. Australasian Plant Pathology 42: 63-72. https://doi.org/10.1007/ s13313-012-0170-2

Shuttleworth LA, Guest DI (2017) The infection process of chestnut rot, an important disease caused by Gnomoniopsis smithogilvyi (Gnomoniaceae, Diaporthales) in Oceania and Europe. Australasian Plant Pathology 46: 397-405. https://doi.org/10.1007/s13313-017-0502-3

Shuttleworth LA, Walker DM, Guest DI (2015) The chestnut pathogen Gnomoniopsis smithogilvyi (Gnomoniaceae, Diaporthales) and its synonyms. Mycotaxon 130: 929-940. https://doi.org/10.5248/130.929

Sogonov MV, Castlebury LA, Rossman AY, Mejía LC, White JF (2008) Leaf-inhabiting genera of the Gnomoniaceae, Diaporthales. Studies in Mycology 62: 1-77. https://doi. org/10.3114/sim.2008.62.01

Stamatakis A (2014) RAxML version 8: A tool for phylogenetic analysis and post-analysis of large phylogenies. Bioinformatics 30: 1312-1313. https://doi.org/10.1093/bioinformatics/btu033

Stevanović M, Ristić D, Živković S, Aleksić G, Stanković I, Krstić B, Bulajić A (2019) Characterization of Gnomoniopsis idaeicola, the causal agent of canker and wilting of Blackberry in Serbia. Plant Disease 103: 249-258. https://doi.org/10.1094/PDIS-03-18-0516-RE

Tamura K, Stecher G, Peterson D, Filipski A, Kumar S (2013) MEGA6: molecular evolutionary genetics analysis version 6.0. Molecular Biology and Evolution 30: 2725-2729. https:// doi.org/10.1093/molbev/mst197

Trapiello E, Feito I, González AJ (2018) First report of Gnomoniopsis castaneae causing canker on hybrid plants of Castanea sativa $\times$ C. crenata in Spain. Plant Disease 102: 1-1040. https://doi.org/10.1094/PDIS-12-17-1874-PDN

Visentin I, Gentile S, Valentino D, Gonthier P, Tamietti G, Cardinale F (2012) Gnomoniopsis castanea sp. nov.(Gnomoniaceae, Diaporthales) as the causal agent of nut rot in sweet chestnut. Journal of Plant Pathology 94: 411-419.

Walker DM, Castlebury LA, Rossman AY, Sogonov MV, White JF (2010) Systematics of genus Gnomoniopsis (Gnomoniaceae, Diaporthales) based on a three gene phylogeny, host associations and morphology. Mycologia 102: 1479-1496. https://doi.org/10.3852/10-002

White TJ, Bruns T, Lee S, Taylor J (1990) Amplification and direct sequencing of fungal ribosomal RNA genes for phylogenetics. PCR protocols: a guide to methods and applications 18: 315-322. https://doi.org/10.1016/B978-0-12-372180-8.50042-1

Yi SJ (2017) Situation and development strategy of chestnut industry in China. Journal of West China Forestry Science 46: 132-149. https://doi:10.16473/j.cnki.xblykx1972.2017.05.023

Zhang HW, Zhang GZ, Cao QC, Sun MD, Cao J (2009) Investigations of main kinds of pests on Chinese chestnut in Beijing. Plant Protection 35: 121-124. 